\title{
QUALIDADE E VALOR NUTRITIVO DAS SILAGENS DE TRÊS HÍBRIDOS DE SORGO (Sorghum bicolor L.) COLHIDOS EM DIFERENTES ESTÁDIOS DE MATURAÇÃO
}

\author{
DANIEL ANANIAS DE ASSIS PIRES ${ }^{1}$, ROBERTO GUIMARÃES JÚNIOR ${ }^{2}$, DIOGO GONZAGA \\ JAYME$^{2}$, LÚCIO CARLOS GONÇALVES ${ }^{3}$, JOSÉ AVELINO SANTOS RODRIGUES ${ }^{4}$, NORBERTO \\ MARIO RODRIGUEZ ${ }^{3}$, IRAN BORGES ${ }^{3}$, ANA LUÍZA COSTA CRUZ BORGES ${ }^{3}$ e CRISTIANO \\ GONZAGA JAYME ${ }^{2}$
}

\begin{abstract}
${ }^{1}$ Médico Veterinário, Doutorando em Ciência Animal, EV-UFMG. Avenida Montes Claros, $n^{\circ}$ 316, Pernambuco. Bocaiúval MG - CEP: 39390-000.Tel: (38) 3251-3925, piresdaa@hotmail.com (Autor para correspondência)

${ }^{2}$ Médico Veterinário, Doutorando em Ciência Animal na EV-UFMG. Escola de Veterinária da UFMG. AV. Antônio Carlos 6627, Pampulha. Belo Horizonte/MG - CEP: 30123-970.

${ }^{3}$ Professor do Departamento de Zootecnia da Escola de Veterinária da UFMG. AV. Antônio Carlos 6627, Pampulha. Belo Horizonte, MG - CEP: 30123-970.

${ }^{4}$ Pesquisador da EMBRAPA Milho e Sorgo, Sete Lagoas,MG.
\end{abstract}

Revista Brasileira de Milho e Sorgo, v.5, n.2, p.241-256, 2006

\begin{abstract}
RESUMO - Dois híbridos de sorgo de porte médio e colmo seco e um híbrido de porte alto e colmo suculento foram ensilados em oito estádios de maturação, a partir do florescimento. Foram 24 tratamentos com três repetições cada, sendo os três híbridos (AG 2006 e BR 700 - colmo seco, e BR 601 - colmo suculento) colhidos em oito estádios de maturação. Foram determinados os teores de MS, PB, perdas de MS, densidade, $\mathrm{pH}$, nitrogênio amoniacal $\left(\mathrm{N}-\mathrm{NH}_{3}\right)$, fibra em detergente neutro (FDN), hemicelulose, celulose e lignina, DIVMS e porcentagem de fenóis totais. Utilizou-se o teste SNK para comparação das médias, com um delineamento inteiramente casualizado, em esquema fatorial 3x8. Com o avanço do estádio de maturação, ocorreu aumento na produção de MS até o quinto estádio. Houve, ainda, aumento nos teores de MS, que atingiram o nível ideal entre 21 e 28 dias após o florescimento. Os teores de PB e das frações fibrosas reduziram-se com a maturidade. Obtiveram-se baixos níveis de $\mathrm{pH}$ e $\mathrm{N}_{-} \mathrm{NH}_{3}$ em todas as silagens, além de baixas perdas de MS. Os híbridos tiveram comportamentos diferentes nos parâmetros lignina e DIVMS. Avaliaram-se os fenóis totais pelo método de azul da Prússia e todas as silagens apresentaram-se com tanino. Não foi encontrada correlação negativa entre os fenóis e a DIVMS. O híbrido AG2006 foi superior aos outros dois híbridos em algumas características e o híbrido BR 601 apesar de ser de porte alto, foi superior ao híbrido BR 700, de duplo propósito, nas variáveis DIVMS e frações fibrosas.
\end{abstract}

Palavras-chave: ensilagem, forragem, nutrição animal, ruminantes

\section{QUALITY AND NUTRITIONAL VALUE OF SILAGES OF THREE SORGHUM (Sorghum bicolor L.) HYBRIDS HARVESTED IN DIFFERENT MATURATION STAGES}

\begin{abstract}
Two dry stem intermediate height sorghum hybrids and a moist stem high height hybrid were ensiled in eight growing stages after bloom. Twenty four
\end{abstract}


treatments were made with three repetitions each, being the three hybrids (AG2006 and BR700 - dry stem, and BR601 moist stem) ensiled in eight growing stages. Silages were evaluated for dry matter (DM), crude protein (CP), DM losses, silage density, $\mathrm{pH}$, ammoniacal nitrogen (N-NH3), neutral detergent fiber (NDF), hemicellulose, cellulose and lignin, IVDMD and total phenols percentages. SNK test was used with a $3 \times 8$ random factorial design. DM production increased until fifth stage. DM values increased with growth and the best level occurred between $21^{\text {st }}$ and $28^{\text {th }}$ days after bloom. $\mathrm{CP}$ and fibrous fractions were reduced with growth. $\mathrm{pH}, \mathrm{N}-\mathrm{NH} 3$ and DM losses were low for all silages. Hybrids lignin and IVDMD varied in erratic ways. Silages were evaluated by Prussian blue assay to total phenols and tannins were detected in all of them. There were no negative correlations between tannins and IVDMD. AG2006 was better than the others two hybrids for some features, and IVDM of BR601, a forage sorghum, was better than BR700, an intermediate height sorghum.

Key words: animal nutrition, ensiling, forage, ruminants

O sorgo é uma das principais forrageiras utilizadas para ensilagem. Existem, no mercado, muitas cultivares, porém nem todas são aptas para a produção de silagem de qualidade. Fatores como digestibilidade do colmo, qualidade dos grãos, resistência a doenças, adaptabilidade ao ambiente e produção de matéria seca afetam diretamente a qualidade da silagem a ser produzida e o desempenho animal na propriedade. A qualidade da silagem vai depender, ainda, do momento de colheita da planta de sorgo, pois o teor de matéria seca vai influenciar o processo fermentativo.

Segundo Paiva (1976), silagens de boa qualidade devem ter a matéria seca entre 30 e $35 \%$. Silagens que apresentem umidade muito alta têm uma série de desvantagens: primeiro, silagens muito úmidas têm um custo de produção maior, pois o transporte por quantidade de matéria seca fica mais caro; segundo, o $\mathrm{pH}$ de silagens muito úmidas tem que ser mais baixo para inibir o crescimento de Clostridio spp. Essas bactérias são indesejáveis por produzirem ácido butírico e degradarem a fração protéica com conseqüente redução do valor nutricional da silagem; terceiro, mesmo que o nível de carboi- dratos solúveis seja o suficiente para promover fermentação lática, o consumo voluntário é diminuído; quarto, silagens muito úmidas produzem efluentes que levam à perda de nutrientes de alta digestibilidade (McDonald et al., 1991).

Assim como o excesso de umidade é ruim para qualidade da silagem, o teor de matéria seca acima de $40 \%$ também é prejudicial, pois estas silagens são mais susceptíveis a danos por aquecimento e aparecimento de fungos, porque a remoção de oxigênio é dificultada, por não permitir uma compactação adequada (Van Soest, 1994). Além disso, a fase aquosa da silagem perde mobilidade. Assim, produtos da fermentação se difundem mais lentamente entre as colônias de bactérias, não ocorrendo uma redução eficaz do $\mathrm{pH}$ para inibir a ação das enzimas da planta, enquanto que, próximo às colônias, torna-se tão ácido que a fermentação é inibida (Moisio \& Heikonen, 1994).

Os valores de $\mathrm{pH}$ das silagens bem conservadas variam entre 3,6 e 4,2. Estas apresentam altas proporções de ácido lático, em relação aos outros ácidos, desde que não se usem aditivos para restringir a fermentação (Fairbairn et al., 1992). Por outro lado, a presença de acetato em 
grandes quantidades está relacionada à ação prolongada de coliformes e das bactérias heterofermentativas, com prejuízo para o balanço energético entre a forragem verde e ensilada (Moisio \& Heikonen, 1994). Segundo Paiva (1976), uma silagem muito boa apresenta valores de $\mathrm{pH}$ entre 3,6 e 3,8; uma silagem boa entre 3,8 e 4,2; uma silagem média, entre 4,2 e 4,6; uma silagem ruim apresenta valores de $\mathrm{pH}$ maiores que 4,6. Segundo McDonald et al. (1991), as bactérias láticas podem ser homofermentativas ou heterofermentativas. As primeiras convertem glicose e frutose em ácido lático e são predominantes no início do processo fermentativo de silagens bem conservadas. Já as bactérias heterofermentativas produzem, além do ácido lático, ácido acético, etanol e dióxido de carbono, não sendo, por isso, tão eficientes quanto as homofermentativas para promover a redução do $\mathrm{pH}$.

Segundo Leibensperger \& Pitt (1987), na silagem com alto teor de matéria seca (acima de $35 \%$ ), o pH é um critério menos útil para medir qualidade, uma que a falta de água e a alta pressão osmótica podem restringir a fermentação e a produção de ácido; portanto, mesmo com $\mathrm{pH}$ alto, estas silagens podem ser consideradas de boa qualidade. Por outro lado, o aumento de $\mathrm{pH}$ com alto teor de umidade está associado com proteólise, produção de aminas e ácido butírico.

O objetivo deste experimento foi avaliar a qualidade e o valor nutritivo das silagens de três híbridos de sorgo, em três estádios de maturação.

\section{Material e Métodos}

Os híbridos de sorgo avaliados neste experimento, dois híbridos de duplo propósito, porte médio, com colmo seco, AG 2006 e BR 700, e um híbrido forrageiro de porte alto, com colmo suculento, BR 601 foram semeados na área experimental da Embrapa Milho e Sorgo, em Sete
Lagoas, Minas Gerais. A semeadura foi realizada em 27 de dezembro de 1994, em 72 canteiros experimentais de 7,0 m x 3,5 m, utilizando-se cinco linhas por tratamento, espaçadas $0,70 \mathrm{~m}$. Cada genótipo foi semeado em vinte e quatro canteiros, sendo três canteiros as repetições para cada estádio. A adubação de plantio foi equivalente a $350 \mathrm{~kg} / \mathrm{ha}$ de 8-28-16 (NPK) e a de cobertura a $100 \mathrm{~kg} / \mathrm{ha}$ de uréia, de acordo com a análise de solo e a necessidade da cultura.

Os híbridos foram ensilados em oito estádios de maturação $\left(\mathrm{E}_{1}, \mathrm{E}_{2}, \mathrm{E}_{3}, \mathrm{E}_{4}, \mathrm{E}_{5}, \mathrm{E}_{6}, \mathrm{E}_{7} \mathrm{e}\right.$ $\mathrm{E}_{8}$ ), que foram $0,7,14,21,28,35,42$ e 49 dias após o florescimento, correspondendo à condição dos grãos no florescimento, estádio de bocha do pré-leitoso, leitoso, leitoso/pastoso, pastoso, farináceo, duro e seco, respectivamente. No momento de ensilagem, cortou-se rente ao solo o material das linhas centrais, descartando-se $1 \mathrm{~m}$ nas cabeceiras. O material colhido foi moído em picadeira estacionária e imediatamente ensilado. Utilizaram-se 72 silos de laboratório, feitos de "PVC", com $10 \mathrm{~cm}$ de diâmetro e $40 \mathrm{~cm}$ de comprimento. Os silos foram compactados, fechados com tampas de "PVC" dotadas de válvulas tipo "Bunsen" e lacrados com fita crepe. Pesaram-se os silos vazios e logo após foram lacrados.

Os silos foram novamente pesados e abertos 151 dias após a ensilagem, sendo as aberturas feitas a cada sete dias, durante oito semanas. Após a abertura, fez-se uma avaliação visual, anotando-se alterações como a presença de fungos na superfície do material, retirando-se e desprezando-se a camada superficial da silagem. Parte da silagem foi acondicionada em bandejas de alumínio, pesada e levada à estufa de ventilação forçada, à uma temperatura $<60^{\circ} \mathrm{C}$, por 72 horas. Após ficarem à temperatura ambiente, as amostras pré-secas foram pesadas e moídas em moinho estacionário “ThomasWiley”, modelo 4 , 
utilizando-se peneira de $1 \mathrm{~mm}$. Em seguida foram guardados em vidros com tampa para as demais determinações laboratoriais.

Imediatamente após a abertura, outra parte da silagem foi prensada, utilizando-se uma prensa hidráulica Carver, modelo C. Uma parte do suco foi utilizada imediatamente, para determinação do pH, em potenciômetro Beckman, e do nitrogênio amoniacal, utilizando-se óxido de magnésio e cloreto de cálcio (Horwitz, 1980).

Nas amostras pré-secadas e moídas em peneira de $1 \mathrm{~mm}$, foram determinadas a matéria seca $105^{\circ} \mathrm{C}$, proteína bruta (Horwitz, 1980), digestibilidade in vitro da matéria seca (Tilley \& Terry, 1963), fenóis totais (Price \& Butler, 1977), porção fibrosa, pelo método seqüencial segundo, Van Soest et al. (1981), utilizando-se $2 \mathrm{ml}$ de amilase "temamil 1201" do laboratório Novo Nordisk a $1 \%$ na determinação da fibra em detergente neutro.

$\mathrm{O}$ delineamento experimental utilizado foi o inteiramente ao acaso, em um fatorial 8 x 3 (idade de corte $\mathrm{x}$ genótipos), com três repetições, sendo as médias comparadas pelo teste SNK, a $5 \%$ de probabilidade.

\section{Resultados e Discussão}

Na Tabela 1 é mostrada a porcentagem de matéria seca da silagem, e na Tabela 2, encontram-se os dados de perdas de MS. Pode-se observar que não houve efeito do estádio de maturação sobre as médias. Entre os híbridos, houve diferença com o híbrido BR 601, apresentando as maiores perdas de MS. No entanto, os valores

TABELA 1. Porcentagem de matéria seca das silagens de três híbridos de sorgo colhidos em oito estádios de maturação.

\begin{tabular}{|c|c|c|c|c|c|c|c|c|c|}
\hline \multirow[b]{2}{*}{ Híbrido } & \multirow[b]{2}{*}{ E1 } & \multirow[b]{2}{*}{ E2 } & \multirow[b]{2}{*}{ E3 } & \multicolumn{2}{|c|}{ Estádio de maturação ${ }^{1}$} & \multirow[b]{2}{*}{ E6 } & \multirow[b]{2}{*}{ E7 } & \multirow[b]{2}{*}{ E8 } & \multirow[b]{2}{*}{ Média } \\
\hline & & & & E4 & $\begin{array}{l}\text { E5 } \\
\end{array}$ & & & & \\
\hline$\overline{\mathrm{AG} 2006}$ & $22,34 \mathrm{Da}$ & $22,97 \mathrm{Da}$ & $23,93 \mathrm{Da}$ & $30,02 \mathrm{Ca}$ & $33,33 \mathrm{Ca}$ & $38,82 \mathrm{Ba}$ & $43,45 \mathrm{Aa}$ & $47,38 \mathrm{Aa}$ & $32,78^{\mathrm{a}}$ \\
\hline BR700 & $22,22 \mathrm{Da}$ & $22,60 \mathrm{Da}$ & $25,31 \mathrm{Da}$ & $27,87 \mathrm{Da}$ & $32,52 \mathrm{Ca}$ & $39,74 \mathrm{Ba}$ & $44,06 \mathrm{Ba}$ & $51,38 \mathrm{Aa}$ & $33,21 \mathrm{a}$ \\
\hline BR601 & $17,80 \mathrm{Ea}$ & $20,30 \mathrm{DEa}$ & 21,92CDEa & $24,80 \mathrm{BCDa}$ & $28,80 \mathrm{Ba}$ & $29,46 \mathrm{Bb}$ & $35,52 \mathrm{Ab}$ & $26,93 \mathrm{BCb}$ & $25,69 \mathrm{~b}$ \\
\hline Média & $20,78 \mathrm{E}$ & $21,95 \mathrm{E}$ & $23,72 \mathrm{E}$ & $27,56 \mathrm{D}$ & $31,55 \mathrm{C}$ & $36,01 \mathrm{~B}$ & $41,01^{\mathrm{a}}$ & $41,89 \mathrm{~A}$ & \\
\hline
\end{tabular}

${ }^{1}$ Médias seguidas pela mesma letra maiúscula na linha ou maiúscula na coluna não diferem significativamente entre si seguindo teste.

Teste SNK, $\mathrm{P}<0,05, \mathrm{CV}=9,03$

TABELA 2. Perdas de matéria seca das silagens de três híbridos de sorgo colhidos em oito estádios de maturação (dados expressos em porcentagem).

\begin{tabular}{|c|c|c|c|c|c|c|c|c|c|}
\hline \multicolumn{10}{|c|}{ Estádio de maturação $^{1}$} \\
\hline Híbrido & $\mathbf{E 1}$ & E2 & E3 & E4 & E5 & E6 & E7 & E8 & Média \\
\hline AG2006 & $1,38 \mathrm{Bb}$ & $1,42 \mathrm{Ba}$ & $1,56 \mathrm{Ba}$ & $1,06 \mathrm{Ba}$ & $0,87 \mathrm{Ba}$ & $1,38 \mathrm{Ba}$ & $1,30 \mathrm{Ba}$ & $2,87 \mathrm{Aa}$ & $1,48 \mathrm{ab}$ \\
\hline BR700 & $0,65 \mathrm{Ab}$ & $1,43 \mathrm{Aa}$ & $1,32 \mathrm{Aa}$ & $1,06 \mathrm{Aa}$ & $1,03 \mathrm{Aa}$ & $1,07 \mathrm{Aa}$ & $1,33 \mathrm{Aa}$ & $1,19 \mathrm{Ab}$ & $1,13 b$ \\
\hline BR601 & $3,19 \mathrm{Aa}$ & $1,90 \mathrm{Aba}$ & $2,11 \mathrm{Aba}$ & $1,59 \mathrm{Ba}$ & $1,72 \mathrm{Ba}$ & $1,48 \mathrm{Ba}$ & $1,27 \mathrm{Ba}$ & $1,38 \mathrm{Bb}$ & $1,83 \mathrm{a}$ \\
\hline Média & $1,74 \mathrm{~A}$ & $1,58 \mathrm{~A}$ & $1,67 \mathrm{~A}$ & $1,23 \mathrm{~A}$ & $1,21 \mathrm{~A}$ & $1,31 \mathrm{~A}$ & $1,30 \mathrm{~A}$ & $1,81 \mathrm{~A}$ & \\
\hline
\end{tabular}

${ }^{1}$ Médias seguidas pela mesma letra maiúscula na linha ou maiúscula na coluna não diferem significativamente entre si seguindo teste.

Teste SNK, $\mathrm{P}<0,05, \mathrm{CV}=44,94$ 
podem ser considerados extremamente baixos. Borges (1995) encontrou valores de perdas de MS variando entre 8,22 e 12,09\%, trabalhando com sorgo ensilado em silos semelhantes aos deste experimento. Nogueira (1995) não acrescentou resultados conclusivos de perdas de MS, mas os valores encontrados por esse autor foram no máximo $8 \%$. Os baixos valores de perdas de MS podem ser em parte, justificados pela ausência de perdas de efluentes; no entanto, essa não pode ser apontada como única causa, pois Borges (1995) trabalhou com o mesmo tipo de silo e obteve valores mais altos.

Os valores de percentuais de proteína bruta $(\mathrm{PB})$ na matéria seca da silagem encontram-se na Tabela 3. Observou-se redução significativa dessas porcentagens com o avanço do estádio de maturação, nos três híbridos. Andrade \& Carvalho (1992) relataram a ocorrência de pouca alteração na porcentagem de $\mathrm{PB}$ com o avanço do estádio de maturação, avaliando os estádios de grãos leitoso, farináceo e duro. Esmail et al. (1991), trabalhando com sorgo consorciado com soja, também não encontraram efeito do estádio de maturação sobre a porcentagem de PB do material ensilado. No entanto, vários outros trabalhos (Meeske et al, 1993; Bishnoi, 1993 e Tonani, 1995) mostraram queda do nível de PB do sorgo com o avanço do estádio de maturação.

Essa queda pode, em parte, dever-se à redução dos níveis de PB das frações folha e colmo, devido à mobilização do seu nitrogênio para a formação das panículas (Ferraris \& CharlesEdwards, 1986). Carvalho et al. (1992) mostraram queda na porcentagem de $\mathrm{PB}$ do colmo de $1,62 \%$, no estádio de grão leitoso, para 0,64 e 0,85\%, nos estádios de grãos farináceo e duro, respectivamente, e queda na porcentagem de $\mathrm{PB}$ das folhas de $9,97 \%$ para 5,83 e 4,96\% nos mesmos estádios, respectivamente. Bruno et al. (1992) mostraram que a parte com teor mais elevado de $\mathrm{PB}$, em várias cultivares de sorgo, eram as folhas, seguidas pelas panículas e, posteriormente, pelos colmos. Essa observação, associada àquela de Carvalho et al. (1992), que mostrou redução na participação das folhas e aumento da participação das panículas com o avanço do estádio de maturação, permite afirmar que a redução na participação das folhas também pode ter levado à queda da PB com o avanço do estádio de maturação. Vale ressaltar que esse declínio poderia ser contraposto por uma concomitante queda na porcentagem de colmo, que é a fração menos protéica. No entanto, nas condições deste experimento, não se observou diferença signifi-

TABELA 3. Porcentagem de proteína bruta das silagens de três híbridos de sorgo colhidos em oito estádios de maturação.

\begin{tabular}{lccccccccc}
\hline & \multicolumn{7}{c}{ Estádio de maturação } & & \\
Híbrido & E1 & E2 & E3 & E4 & E5 & E6 & E7 & E8 & Média \\
\hline AG2006 & 9,59 & 8,34 & 8,18 & 7,06 & 7,46 & 6,31 & 6,75 & 6,91 & $7,57 \mathrm{a}$ \\
BR700 & 8,49 & 7,79 & 7,32 & 7,14 & 7,07 & 6,66 & 6,37 & 7,69 & $7,31 \mathrm{a}$ \\
BR601 & 7,49 & 7,01 & 6,39 & 6,80 & 5,92 & 6,17 & 6,45 & 6,05 & $6,53 \mathrm{~b}$ \\
\hline Média & $8,52 \mathrm{~A}$ & $7,71 \mathrm{~B}$ & $7,30 \mathrm{BC}$ & $7,00 \mathrm{BC}$ & $6,88 \mathrm{BC}$ & $6,81 \mathrm{BC}$ & $6,52 \mathrm{C}$ & $6,38 \mathrm{C}$ & \\
\hline
\end{tabular}

${ }^{1}$ Médias seguidas pela mesma letra maiúscula na linha ou maiúscula na coluna não diferem significativamente entre si seguindo teste.

Teste SNK, $\mathrm{P}<0,05, \mathrm{CV}=11,54$ 
cativa na porcentagem de colmo a partir da segunda semana.

Sabe-se que a fermentação provoca alterações na composição das frações nitrogenadas, reduzindo os níveis de proteína verdadeira e aumentando os níveis de aminoácidos livres ou produtos da quebra desses aminoácidos, incluindo amônia, $\mathrm{CO}_{2}$ e animas (Oshima \& McDonald, 1978). O nível em que essa proteólise ocorre depende de diversos fatores relacionados ao processo de fermentação (Fairbairn et al., 1992) e a avaliação de silagens quanto aos compostos nitrogenados deve incluir métodos que possam indicar os níveis em que essa proteólise ocorreu. Neste experimento, dosou-se o nível de N-amoniacal no suco das silagens como indicativo do grau de proteólise.

$\mathrm{Na}$ Tabela 4, encontram-se os dados de $\mathrm{N}$-amoniacal, expressos em porcentagem do Ntotal. Pode-se observar que não houve diferença entre os híbridos e que os níveis diminuíram com o avanço do estádio de maturação. Um importante fator que leva a aumento da proteólise é a alta umidade (McDonald et al., 1991), sendo, provavelmente, esse o motivo do maior nível de $\mathrm{N}$-amoniacal nas primeiras semanas.

Apesar de os níveis de $\mathrm{N}$-amoniacal serem maiores que os encontrados por Nogueira
(1995) e Borges (1995), estes estão abaixo de $10 \%$ do N-total, nível considerado por Oshima \& McDonald (1978) como normal em silagens com fermentação lática. Tjandraatmadja et al. (1993) consideram níveis abaixo de $6 \%$ do N-total como características de silagem de alta qualidade.

Segundo Van Soest (1994, a associação de $\mathrm{pH}$ e umidade pode ser um critério simples de avaliação da qualidade das silagens, sendo que, em silagem com baixo teor de MS, a melhor qualidade é obtida com valores de pH abaixo de 4,4. Em silagens com alto teor de MS ( > 35\% MS) o pH é menos importante, podendo-se obter silagens de boa qualidade mesmo com valores de pH mais alto. McDonald et al. (1991) classifica como ideal a obtenção de silagem com pH abaixo de 4,0.

Conforme demonstrado na Tabela 5, todas as silagens tiveram $\mathrm{pH}$ abaixo de 4,0 , podendo, por isso, ser classificadas como ótimas em relação ao valor de $\mathrm{pH}$. Outros autores, como Borges (1995) e Nogueira (1995) encontraram valores de $\mathrm{pH}$ semelhantes aos deste trabalho, após o término do processo de fermentação de silagens de sorgo. Gaggiotti et al. (1992) e Muck \& O'kiely (1992) encontraram valores de $\mathrm{pH}$ entre 4,0 e 4,4, em silagens com padrão de fermentação considerado satisfatório.

TABELA 4. Teores de $\mathrm{N}$ amoniacal expressos em porcentagem do $\mathrm{N}$ total das silagens de três híbridos de sorgo colhidos em oito estádios de maturação.

\begin{tabular}{lccccccccc}
\hline & & \multicolumn{7}{c}{ Estádio de maturação } & \\
\cline { 7 - 9 } Híbrido & E1 & E2 & E3 & E4 & E5 & E6 & E7 & E8 & Média \\
\hline AG2006 & 6,67 & 7,61 & 6,75 & 7,79 & 8,22 & 6,94 & 7,09 & 6,68 & $7,22 \mathrm{a}$ \\
BR700 & 7,17 & 8,33 & 7,22 & 6,96 & 5,23 & 4,98 & 6,46 & 5,53 & $6,48 \mathrm{a}$ \\
BR601 & 6,63 & 7,44 & 8,10 & 6,58 & 6,40 & 6,17 & 5,83 & 5,67 & $6,60 \mathrm{a}$ \\
\hline Média & $6,82 \mathrm{AB}$ & $7,79 \mathrm{~A}$ & $7,36 \mathrm{AB}$ & $7,11 \mathrm{AB}$ & $6,62 \mathrm{AB}$ & $6,03 \mathrm{~B}$ & $6,46 \mathrm{AB}$ & $5,96 \mathrm{~B}$ & \\
\hline
\end{tabular}

${ }^{1}$ Médias seguidas pela mesma letra maiúscula na linha ou maiúscula na coluna não diferem significativamente entre si seguindo teste.

Teste SNK, $\mathrm{P}<0,05, \mathrm{CV}=15,95$ 
Está bem definido que os sorgos utilizados para silagem, no Brasil, geralmente têm um nível de carboidratos solúveis suficiente para uma boa fermentação, com conseqüente queda do $\mathrm{pH}$ (Nogueira, 1995; Borges, 1995). Conforme era esperado, os valores de $\mathrm{pH}$ encontrados permitem afirmar que, nas condições deste experimento, em todos os tratamentos, houve disponibilidade de carboidratos solúveis para uma adequada fermentação. Vale ressaltar que as condições de ensilagem com silos de laboratório são ideais e que, em condições de campo, a necessidade de carboidratos solúveis pode ser maior, em virtude das piores condições de ensilagem (Petterson \& Lindgren, 1990).

Como consta na Tabela 5, apesar de todas as silagens apresentarem valores baixos de $\mathrm{pH}$, houve aumento significativo do $\mathrm{pH}$ com o avanço do estádio de maturação, nos três híbridos. Esmail et al. (1991) encontraram efeito significativo do estádio de maturação dos grãos sobre o $\mathrm{pH}$ de silagens de sorgo, no entanto, no trabalho desses autores, não houve um efeito claro, pois o pH caiu do estádio de florescimento para o estádio de grãos leitosos e subiu do estádio de grãos leitosos para grãos farináceos. Uma possível explicação para o efeito do estádio de maturação sobre o pH é o efeito da umidade. Para Van
Soest (1994), a acidificação é inibida pela falta de água, sendo que o pH é inversamente correlacionado com o teor de umidade. Essa explicação é sustentada pela alta correlação $(r=0,86, p<0,01)$ encontrada entre $\mathrm{pH}$ e matéria seca da silagem. Além disso, o híbrido BR 601, que teve menor aumento no teor de MS com o avanço do estádio de maturação, apresentou menor aumento nos valores de $\mathrm{pH}$. Outra possível explicação seria o nível de carboidratos solúveis do material; no entanto, neste trabalho, não se dosaram os níveis desses carboidratos.

A determinação das frações fibrosas é muito importante na caracterização de forragens quanto ao seu valor nutritivo. Segundo Minson (1990), as frações FDN, FDA e lignina são negativamente correlacionadas com a digestibilidade e, conseqüientemente, com o valor energético das forragens. Além disso, Van Soest (1994) afirmou que os teores de FDN das forragens são negativamente correlacionados com o consumo das mesmas. A digestibilidade e o consumo de uma forragem são determinantes do valor dessa para a nutrição animal e, sendo esses dois parâmetros de difícil determinação em nível de rotina de laboratório, o uso das frações fibrosas para estimá-los pode ser de grande utilidade. Assim, silagens com menores frações fibrosas tendem a ter

TABELA 5. Valores de pH das silagens de três híbridos de sorgo colhidos em oito estádios de maturação.

\begin{tabular}{|c|c|c|c|c|c|c|c|c|c|}
\hline \multirow[b]{2}{*}{ Híbrido } & \multirow[b]{2}{*}{ E1 } & \multirow[b]{2}{*}{$\mathbf{E 2}$} & \multirow[b]{2}{*}{ E3 } & \multicolumn{2}{|c|}{ Estádio de maturação } & \multirow[b]{2}{*}{ E6 } & \multirow[b]{2}{*}{ E7 } & \multirow[b]{2}{*}{ E8 } & \multirow[b]{2}{*}{ Média } \\
\hline & & & & E4 & E5 & & & & \\
\hline AG2006 & $3,57 \mathrm{Ca}$ & $3,56 \mathrm{Ca}$ & $3,61 \mathrm{Ca}$ & $3,61 \mathrm{Ca}$ & $3,60 \mathrm{Ca}$ & $3,79 \mathrm{Bab}$ & $3,93 \mathrm{Aa}$ & $3,94 \mathrm{Aa}$ & $3,70 \mathrm{a}$ \\
\hline BR700 & $3,53 \mathrm{Ba}$ & $3,50 \mathrm{Ba}$ & $3,55 \mathrm{Ba}$ & $3,51 \mathrm{Ba}$ & $3,55 \mathrm{Ba}$ & $3,84 \mathrm{Aa}$ & $3,88 \mathrm{Aa}$ & $3,95 \mathrm{Aa}$ & $3,67 \mathrm{a}$ \\
\hline BR601 & $3,53 \mathrm{Bca}$ & $3,50 \mathrm{Ca}$ & $3,54 \mathrm{Bca}$ & $3,55 \mathrm{Bca}$ & $3,66 \mathrm{Aba}$ & $3,70 \mathrm{Ab}$ & $3,77 \mathrm{Ab}$ & $3,68 \mathrm{Ab}$ & $3,62 b$ \\
\hline Média & $3,54 \mathrm{C}$ & $3,52 \mathrm{C}$ & $3,56 \mathrm{C}$ & $3,56 \mathrm{C}$ & $3,60 \mathrm{C}$ & $3,78 \mathrm{~B}$ & $3,86 \mathrm{~A}$ & $3,85^{\mathrm{a}}$ & \\
\hline
\end{tabular}

${ }^{1}$ Médias seguidas pela mesma letra maiúscula na linha ou maiúscula na coluna não diferem significativamente entre si seguindo teste.

Teste SNK, $\mathrm{P}<0,05, \mathrm{CV}=1,72$ 
maior digestibilidade e maior consumo, desde que não existam outros fatores envolvidos (Minson, 1990; Van Soest, 1994).

A Tabela 6 mostra os valores de FDN, hemicelulose e celulose das silagens e pode-se observar que os níveis de FDN reduziram-se à medida que avançou o estádio de maturação, nos três híbridos. Houve uma redução significativa das três primeiras para a quarta semana, quando houve uma tendência de estabilização até a oitava semana. No híbrido BR 700, houve redução da porcentagem de FDN da sétima para a oitava semana. Os valores de FDN observados encontram-se em uma faixa semelhante aos relatados por outros autores, como Bruno et al. (1992), Sanderson (1993) e Borges (1995). Com relação ao efeito do estádio de maturação sobre os teores de FDN, existem resultados diversos na literatura. Hart (1990) não detectou diferença do estádio de grão leitoso para o estádio maduro. No entanto Danley \& Vetter (1973) registraram aumento do nível de FDN com o avanço do estádio de maturação de um sorgo forrageiro. Já Tonani (1995) encontrou uma tendência de queda do nível de FDN do estádio de grãos leitosos para grãos pastosos e tendência de aumento do estádio de grão pastosos para grãos farináceos. Os resultados de Esmail et al. (1991) e Bishnoi et al. (1993) concordam com os deste trabalho, ou seja, mostram redução nos níveis de FDN das silagens com o avanço do estádio de maturação.

A redução nos níveis de FDN com o avanço do estádio de maturação provavelmente ocorreu em função do aumento de participação das panículas e redução da participação de colmos e folhas no material ensilado. Bruno et al. (1992) mostraram que o maior teor de FDN foi encontrado nas folhas seguidas pelos colmos. Hart

TABELA 6. Teores de FDN, hemicelulose e celulose das silagens de três híbridos de sorgo colhidos em oito estádios de maturação (dados expressos em porcentagem da matéria seca).

\begin{tabular}{|c|c|c|c|c|c|c|c|c|c|}
\hline \multirow[b]{2}{*}{ Híbrido } & \multirow[b]{2}{*}{ E1 } & \multirow[b]{2}{*}{$\mathbf{E} 2$} & \multirow[b]{2}{*}{ E3 } & \multicolumn{2}{|c|}{ Estádio de maturação ${ }^{1}$} & \multirow[b]{2}{*}{ E6 } & \multirow[b]{2}{*}{ E7 } & \multirow[b]{2}{*}{ E8 } & \multirow[b]{2}{*}{ Média } \\
\hline & & & & E4 & E5 & & & & \\
\hline \multicolumn{10}{|c|}{ Teor de FDN } \\
\hline AG2006 & $66,20 \mathrm{Aa}$ & $60,89 \mathrm{Aa}$ & $59,99 \mathrm{Aa}$ & $51,47 \mathrm{Bb}$ & $46,35 \mathrm{Bb}$ & $49,56 \mathrm{Bb}$ & $44,74 \mathrm{Bb}$ & $47,61 \mathrm{Ba}$ & $53,35 \mathrm{c}$ \\
\hline BR700 & $64,78 \mathrm{ABa}$ & $66,14 \mathrm{Aa}$ & $63,34 \mathrm{ABa}$ & $60,40 \mathrm{ABa}$ & $57,77 \mathrm{Ba}$ & $57,63 \mathrm{Ba}$ & $57,54 \mathrm{Ba}$ & $49,87 \mathrm{Ca}$ & $59,68 \mathrm{a}$ \\
\hline BR601 & $63,97 \mathrm{Aa}$ & $63,23 \mathrm{Aa}$ & $57,22 \mathrm{ABa}$ & $52,29 \mathrm{Bb}$ & $53,76 \mathrm{Ba}$ & $52,95 \mathrm{Bab}$ & $51,75 \mathrm{Ba}$ & $54,08 \mathrm{Ba}$ & $56,15 b$ \\
\hline Média & $64,98 \mathrm{~A}$ & $63,42 \mathrm{AB}$ & $60,18 \mathrm{~B}$ & $54,72 \mathrm{C}$ & $52,62 \mathrm{C}$ & $53,38 \mathrm{C}$ & $51,34 \mathrm{C}$ & $50,52 \mathrm{C}$ & \\
\hline \multicolumn{10}{|c|}{ Teor de hemicelulose } \\
\hline AG2006 & $28,53 \mathrm{Aa}$ & $25,66 \mathrm{Ba}$ & $25,45 \mathrm{Bab}$ & $21,93 \mathrm{Cb}$ & $19,89 \mathrm{Cb}$ & $20,99 \mathrm{Ca}$ & $19,51 \mathrm{Cb}$ & $20,97 \mathrm{Ca}$ & $22,86 \mathrm{~b}$ \\
\hline$\overline{B R 700}$ & $27,58 \mathrm{Aa}$ & $27,24 \mathrm{Aa}$ & $26,57 \mathrm{Aa}$ & $25,35 \mathrm{Aa}$ & $24,48 \mathrm{Aa}$ & $23,94 \mathrm{Aa}$ & $24,03 \mathrm{Aa}$ & $20,54 \mathrm{Ba}$ & $24,96 a$ \\
\hline BR601 & $26,70 \mathrm{Aa}$ & $26,28 \mathrm{Aa}$ & $23,08 \mathrm{Bb}$ & $22,03 \mathrm{Bb}$ & $22,05 \mathrm{Bab}$ & $22,00 \mathrm{Ba}$ & $22,61 \mathrm{Ba}$ & $22,31 \mathrm{Ba}$ & $23,38 b$ \\
\hline Média & $27,60 \mathrm{~A}$ & $26,39 \mathrm{~A}$ & $25,03 \mathrm{~B}$ & $23,10 \mathrm{C}$ & $22,14 \mathrm{C}$ & $22,31 \mathrm{C}$ & $22,05 \mathrm{C}$ & $21,27 \mathrm{C}$ & \\
\hline \multicolumn{10}{|c|}{ Teor de celulose } \\
\hline AG2006 & 33,69 & 31,36 & 30,20 & 26,11 & 23,32 & 24,97 & 21,72 & 23,00 & $26,79 b$ \\
\hline BR700 & 33,52 & 34,28 & 32,07 & 30,14 & 28,19 & 27,94 & 27,42 & 23,96 & $29,69 a$ \\
\hline BR601 & 33,47 & 32,73 & 30,41 & 26,83 & 28,00 & 27,16 & 24,67 & 26,70 & $28,75 \mathrm{a}$ \\
\hline Média & $33,56 \mathrm{~A}$ & $32,79 \mathrm{~A}$ & $30,89 \mathrm{~A}$ & $27,69 \mathrm{~B}$ & $26,50 \mathrm{BC}$ & $26,69 \mathrm{BC}$ & $24,60 \mathrm{C}$ & $24,55 \mathrm{C}$ & \\
\hline
\end{tabular}

${ }^{1}$ Médias seguidas pela mesma letra maiúscula na linha ou maiúscula na coluna não diferem significativamente entre si seguindo teste.

Teste SNK, $\mathrm{P}<0,05, \mathrm{CV}=6,26$ 
(1990) provocou aumento na porcentagem de grãos da silagem elevando a altura de corte e constatou redução dos teores de FDN à medida que aumentou a porcentagem de grãos. As correlações encontradas entre teor de FDN e porcentagem de folhas $(r=0,66, p<0,01)$, porcentagem de colmo ( $\mathrm{r} 0,48, \mathrm{p}<0,01)$ e porcentagem de panícula $(\mathrm{r}=-0,78, \mathrm{p}<0,01)$ sustentam a afirmação de que a queda do teor de FDN foi provocada pela alteração na participação das diferentes partes no material ensilado, à medida em que crescia a porcentagem de panículas.

$\mathrm{Na}$ Tabela 6, observa-se que o híbrido AG2006 apresentou os menores valores de FDN, seguido pelo híbrido BR 601 e, posteriormente, pelo híbrido BR 700. Existe uma tendência de se associar à altura do híbrido a maior ou menor porcentagem de panículas na massa ensilada, e, consequientemente, a maior ou menor nível de fibra na silagem. Essa afirmativa pode ser confirmada por resultados como o de Nogueira (1995), que, trabalhando com híbridos de porte baixo, encontrou teores de FDN mais baixos que outros autores, como Gaggioti et al. (1992) e Borges (1995), que trabalharam com híbridos de porte alto. Neste trabalho, ao contrário do que se esperava, o híbrido BR 700, apesar de ser de porte mais baixo que o híbrido BR 601 não apresentou maior proporção de panículas e apresentou teores mais elevados de FDN, que o híbrido BR 601.

Conforme a Tabela 6, onde estão os dados de porcentagem de hemicelulose na MS das silagens, determinada pela diferença entre FDN e FDA, o híbrido AG 2006, teve queda dos níveis de hemicelulose até a quarta semana e, da quarta a oitava semana, não houve diferença significativa. No híbrido BR601 a queda aconteceu até a terceira semana e a partir dai não houve diferença significativa. No híbrido BR 700, apesar de haver queda com o avanço do estádio de ma- turação, só houve diferença significativa entre a sétima e oitava semanas.

Os híbridos AG 2006 e BR 601 apresentaram teores médios de hemicelulose das silagens iguais entre si e inferiores ao teor médio do híbrido BR 700. Quando se considera os híbridos dentro de cada estádio de maturação, o maior nível de hemicelulose do híbrido BR 700 comparado aos outros dois híbridos só foi encontrado no terceiro, quarto e quinto estádios. No sétimo estádio, o híbrido AG 2006 apresentou nível de hemicelulose menor que os outros dois híbridos, que não diferiram entre si.

Os valores de porcentagem de hemicelulose são semelhantes aos de outros autores, como Tjandratmaja et al. (1993) e Nogueira (1995). Borges (1995), trabalhando com sorgo de porte alto, encontrou valores de hemicelulose superiores aos deste trabalho. McBee \& Miller (1990) encontraram valores de hemicelulose das folhas e dos colmos de sorgo variando de 27,4 a $31,0 \%$ e 21,6 a $26,5 \%$, respectivamente.

Os teores de celulose nas silagens, em porcentagem da MS, foram determinados por diferença, subtraindo da FDA a lignina e as cinzas insolúveis. Esses valores encontram-se na Tabela 6. À medida em que avançou o estádio de maturação, houve queda nos teores de celulose. Esse efeito está diretamente ligado ao ocorrido com FDN e FDA, pois a celulose é um importante componente dessas duas frações. Assim, as causas desse efeito devem ser as mesmas que levaram à ocorrência de comportamento semelhante nos parâmetros FDN e FDA.

O híbrido AG 2006 apresentou porcentagem de celulose inferior aos outros dois híbridos, que não diferiram entre si. Os valores encontrados são semelhantes aos encontrados por Danley \& Vetter (1973) e Tjandraatmadja et al. (1993). Valores inferiores aos deste trabalho fo- 
ram encontrados por Nogueira (1995) e Borges (1995).

Os níveis de lignina de uma forrageira são inversamente correlacionados com a digestibilidade da mesma (Hanna et al., 1981; Nogueira, 1995). O efeito antinutricional da lignina parece ser modulado pela natureza e pelo grau de suas associações com a parede celular, na forma de complexos lignina-carboidratos (Goto et al., 1991). Os teores de lignina nas silagens, expressos em porcentagem da MS, estão apresentados na Tabela 7.

Com o avanço do estádio de maturação, houve aumento na porcentagem de lignina nos híbridos BR 601 e BR 700. No híbrido AG 2006, não houve diferença entre os estádios, na porcentagem de lignina, com o avanço do estádio de maturação. Diversos autores encontraram aumento no teor de lignina do sorgo com o avanço do estádio de maturação (Danley \& Vetter, 1973; Hanna et al., 1981; Goto et al., 1991), esse aumento provavelmente ocorre em função da lignificação das partes vegetativas, da planta com o avanço da maturação (McBee \& Miller, 1993). No híbrido AG 2006 pode ter ocorrido uma compensação do aumento do teor de lignina nas partes vegetativas pelo aumento na participação dos grãos, já que esse híbrido possui maior porcenta- gem de grãos. Além disso, o avanço do estádio de maturação pode ter efeito diferente com relação ao acúmulo de lignina em diferentes materiais (Danley \& Vetter, 1973).

A partir da quarta semana, o híbrido BR 700 apresentou teores de lignina significativamente maiores que os outros dois híbridos. Os híbridos AG 2006 e BR 601 só diferiram nas duas últimas semanas com os menores teores de lignina ocorrendo no AG 2006. Na média dos oito estádios de maturação, o híbrido AG 2006 apresentou porcentagem de lignina inferior ao híbrido BR 601 que teve valor inferior ao híbrido BR 700. Os valores encontrados para porcentagem de lignina são semelhantes ao de outros autores, como Nogueira (1995) e Borges (1995)

O potencial de consumo de uma forragem por um ruminante é um componente fundamental da qualidade dessa forragem. Existe uma relação entre o consumo e a digestibilidade da forragem. Além disso, a digestibilidade da forragem é uma medida do valor energético da mesma, pois existe alta correlação entre energia digestível e energia metabolizável (Minson, 1990). Segundo Tilley \& Terry (1963), os resultados de digestibilidade in vitro de matéria seca (DIVMS) são altamente correlacionados com os valores de

TABELA 7. Teores de lignina das silagens de três híbridos de sorgo colhidos em oito estádios de maturação expressos em porcentagem da matéria seca.

\begin{tabular}{llllllllll}
\hline & \multicolumn{8}{c}{ Estádio de maturaçã ${ }^{1}$} \\
Híbrido & E1 & E2 & E3 & \multicolumn{1}{c}{ E4 } & \multicolumn{1}{c}{ E5 } & E6 & E7 & E8 & Média \\
\hline AG2006 & $3,88 \mathrm{Aa}$ & $3,68 \mathrm{Aa}$ & $4,24 \mathrm{Aa}$ & $3,39 \mathrm{Ab}$ & $3,07 \mathrm{Ab}$ & $3,49 \mathrm{Ab}$ & $3,47 \mathrm{Ac}$ & $3,56 \mathrm{Ab}$ & $3,60 \mathrm{c}$ \\
BR700 & $3,65 \mathrm{Da}$ & $4,34 \mathrm{CDa}$ & $4,61 \mathrm{BCDa}$ & $4,91 \mathrm{ABCa}$ & $5,02 \mathrm{ABCa}$ & $5,72 \mathrm{ABa}$ & $5,95 \mathrm{Aa}$ & $5,33 \mathrm{ABCa}$ & $4,94 \mathrm{a}$ \\
BR601 & $3,70 \mathrm{ABa}$ & $4,16 \mathrm{ABa}$ & $3,71 \mathrm{ABa}$ & $3,23 \mathrm{Bb}$ & $3,63 \mathrm{ABb}$ & $3,72 \mathrm{ABb}$ & $4,35 \mathrm{Abb}$ & $4,70 \mathrm{Aa}$ & $3,90 \mathrm{~b}$ \\
\hline Média & $3,74 \mathrm{C}$ & $4,06 \mathrm{ABC}$ & $4,18 \mathrm{ABC}$ & $3,84 \mathrm{BC}$ & $3,90 \mathrm{ABC}$ & $4,31 \mathrm{ABC}$ & $4,59^{\mathrm{a}}$ & $4,53 \mathrm{AB}$ & \\
\hline
\end{tabular}

${ }^{1}$ Médias seguidas pela mesma letra maiúscula na linha ou maiúscula na coluna não diferem significativamente entre si seguindo teste.

Teste $\mathrm{SNK}, \mathrm{P}<0,05, \mathrm{CV}=12,30$ 
digestibilidade in vivo. Na Tabela 8, encontramse os valores de DIVMS da silagem.

Pode-se observar que os híbridos tiveram um comportamento diferente quanto a DIVMS nos diferentes estádios de maturação. O híbrido AG 2006 apresentou maior digestibilidade na quarta semana e menor digestibilidade na sexta semana. O híbrido BR 700 apresentou na sétima semana DIVMS inferior $(\mathrm{p}<0,05)$ às demais, que não diferiram entre si $(\mathrm{p}>0,05)$. $\mathrm{O}$ híbrido BR 601 apresentou queda da DIVMS com o avanço do estádio de maturação. Apesar da tendência de queda gradativa da DIVMS com o avanço da maturidade, houve um crescimento na sétima semana, quando se encontrou a maior média de DIVMS das silagens desse híbrido.

Alguns autores, como Zago (1991), afirmaram que, como as panículas são a fração mais digestível da planta de sorgo, o aumento da proporção dessa fração com o avanço da maturidade pode ser responsável por aumento da digestibilidade. Essa pode ser a explicação para a maior digestibilidade do híbrido AG 2006 na quarta e quinta semanas. No entanto, assim como neste trabalho, o efeito do estádio de maturação sobre a digestibilidade é variável em diferentes materiais. Esmail et al. (1991) não encontraram efeito de estádio de maturação sobre a digestibilidade de diversas frações da planta de sorgo. Hart
(1990) e Andrade \& Carvalho (1992) não encontraram diferenças na digestibilidade mesmo quando a proporção de grãos era aumentada; o primeiro, por elevação na altura de corte e o segundo, por avanço no estádio de maturação. Hart (1990) afirmou que a queda da digestibilidade das frações FDN, FDA, PB, amido e conteúdo celular pode ser responsável por redução na DIVMS com o avanço do estádio de maturação. Danley \& Vetter (1973) e Hanna et al. (1981) encontraram redução na digestibilidade com avanço do estádio de maturação e apontaram o aumento da fração lignina como o maior responsável por essa queda. Tonani (1995) também encontrou redução na digestibilidade da planta do estádio de grãos leitosos para grãos farináceos, essa autora atribuiu esse efeito à redução da digestibilidade da parte vegetativa das plantas e ao aumento da dureza dos grãos.

Comparando-se os três híbridos, pode-se observar que, na média das DIVMS, o AG 2006 foi superior $(\mathrm{p}<0,05)$ ao BR 601 que foi superior $(\mathrm{p}<0,05)$ ao BR 700. Não houve diferença entre os híbridos nos estádios 1, 2, 3 e 7. Nos demais estádios, o híbrido AG 2006 apresentou os maiores valores de DIVMS.

Zago (1991) apontou o porte dos híbridos de sorgo como indicador da proporção de grãos do material, sorgo granífero (porte baixo),

TABELA 8. Digestibilidade in vitro da matéria seca das silagens de três híbridos de sorgo colhidos em oito estádios de maturação, expressa em porcentagem.

\begin{tabular}{|c|c|c|c|c|c|c|c|c|c|}
\hline \multicolumn{10}{|c|}{$\underline{\text { Estádio de maturação }}^{1}$} \\
\hline Híbrido & E1 & E2 & E3 & E4 & E5 & E6 & E7 & E8 & Média \\
\hline AG2006 & $58,11 \mathrm{ABa}$ & $58,94 \mathrm{ABa}$ & $57,89 \mathrm{ABa}$ & $60,56 \mathrm{Aa}$ & $57,79 \mathrm{ABa}$ & $54,78 \mathrm{Ba}$ & $57,58 \mathrm{ABa}$ & $56,72 \mathrm{ABa}$ & $57,79 a$ \\
\hline BR700 & $57,71 \mathrm{Aa}$ & $55,94 \mathrm{Aa}$ & $56,35 \mathrm{Aa}$ & $56,29 \mathrm{Ab}$ & $53,52 \mathrm{ABb}$ & $54,56 \mathrm{Aa}$ & $50,23 \mathrm{Bb}$ & $54,87 \mathrm{Aab}$ & $54,93 \mathrm{c}$ \\
\hline BR601 & $57,31 \mathrm{ABa}$ & $58,09 \mathrm{ABa}$ & $57,64 \mathrm{ABa}$ & $55,48 \mathrm{ABCb}$ & $56,59 \mathrm{ABCab}$ & $54,02 \mathrm{BCa}$ & $59,23 \mathrm{Aa}$ & $52,53 \mathrm{Cb}$ & $56,36 \mathrm{~b}$ \\
\hline Média & $57,71^{\mathrm{a}}$ & $57,66 \mathrm{~A}$ & $57,29 \mathrm{~A}$ & $57,49 \mathrm{~A}$ & $55,97 \mathrm{AB}$ & $54,45 \mathrm{~B}$ & $55,68 \mathrm{AB}$ & $54,70 \mathrm{~B}$ & \\
\hline
\end{tabular}

${ }^{1}$ Médias seguidas pela mesma letra maiúscula na linha ou maiúscula na coluna não diferem significativamente entre si seguindo teste.

Teste SNK, $\mathrm{P}<0,05, \mathrm{CV}=3,58$ 
sorgo duplo propósito (porte médio) e sorgo forrageiro (porte alto). Salako \& Felix (1986) encontraram maior DIVMS em sorgos graníferos que em sorgos sacarinos de porte alto. No entanto, os resultados deste trabalho vêm mostrar que a altura da planta pode não retratar a proporção de grãos e, principalmente, a digestibilidade do material, pois o híbrido BR 601, de porte alto, apresentou maior digestibilidade que o híbrido BR 700, de porte médio, e digestibilidade semelhante à do híbrido AG 2006, também de porte médio. Pereira et al. (1993) avaliaram sorgos de porte alto, médio e baixo e não encontraram diferença na digestibilidade da matéria seca e matéria orgânica.

A porcentagem de grãos é um importante parâmetro de avaliação da qualidade do sorgo. Diversos autores chamam a atenção para essa característica e sua correlação positiva com a digestibilidade e o valor energético do sorgo (Cummins, 1971; Salako \& Felix, 1986; Hunt et al., 1993). No entanto, resultados como os de Hart (1990); Andrade \& Carvalho (1992) e Hunt et al. (1993), em que não se demonstrou aumento da digestibilidade com o aumento da proporção de grãos, chamam a atenção para a existência de outros importantes fatores que podem ser levados em conta para promover o desenvolvimento de materiais com maior potencial.

Encontrou-se correlação negativa entre a DIVMS e a lignina $(r=-0,56, p<0,01)$. A lignina é apontada como responsável por efeitos negativos sobre a digestibilidade em vários trabalhos (Hanna et al., 1981; Lusk et al., 1984; Thorstensson , 1992). Segundo Thorstensson (1992), a composição da lignina pode exercer maior influência sobre a digestibilidade que sua concentração. Danley \& Vetter (1973) afirmaram que o efeito da lignina está intimamente relacionado à relação lignina/celulose ou a relação lignina/FDA.
Frações da fibra, como a FDN e a FDA, geralmente apontados como relacionados à digestibilidade não apresentaram correlação significativa neste experimento.

A avaliação do teor de tanino das silagens foi realizada utilizando-se o método Azul da Prússia (Price \& Butler, 1977). Os dados apresentados na Tabela 9 representam a porcentagem de fenóis totais, pois o método não distingue os taninos dos fenóis de baixo peso molecular (que não têm efeito adverso na qualidade nutricional). Segundo Hahn et al. (1984), os compostos fenólicos, nos sorgos, podem ser divididos em três grupos básicos: ácidos fenólicos, flavonóides e taninos. Todo sorgo contém ácidos fenólicos e muitos contêm flavonóides. Somente o sorgo com alto teor de tanino contém tanino condensado.

Como pode-se observar na Tabela 9, a porcentagem de fenóis totais das silagens diminuiu com o avanço do estádio de maturação dos três híbridos. Montgomery et al. (1986) apud Rodrigues (1991), avaliando 12 híbridos de sorgo granífero e forrageiro, observaram reduções significativas no teor de tanino entre as fases de grão leitoso, pastoso e maturação fisiológica, em sorgo com alto tanino. No entanto, não observaram diferenças entre os estádios nos sorgos de baixo tanino, no grão. Rogler \& Butler (s.d.) também encontraram redução do teor de tanino dos grãos com o avanço do estádio de maturação, em sorgo de alto tanino, e ausência desse efeito em sorgo de baixo tanino.

Rodrigues (1991) encontrou valores máximos de tanino quando os grãos estavam leitosos, com redução a partir desse estádio. Esse efeito ocorreu em diversos materiais, incluindo os de baixo tanino. Segundo esse autor, a redução do teor de tanino ao longo da maturação do grão provavelmente se deve ao fato de que os compostos fenólicos em sorgo são substâncias pre- 
TABELA 9. Porcentagem de fenóis totais das silagens de três híbridos de sorgo colhidos em oito estádios de maturação determinados pelo método Azul da Prússia.

\begin{tabular}{|c|c|c|c|c|c|c|c|c|c|}
\hline \multirow[b]{2}{*}{ Híbrido } & \multirow[b]{2}{*}{ E1 } & \multirow[b]{2}{*}{ E2 } & \multicolumn{4}{|c|}{${\text { Estádio de maturação }{ }^{1}}^{1}$} & \multirow[b]{2}{*}{ E7 } & \multirow[b]{2}{*}{ E8 } & \multirow[b]{2}{*}{ Média } \\
\hline & & & E3 & E4 & E5 & E6 & & & \\
\hline AG2006 & 1,33 & 1,46 & 1,39 & 1,25 & 1,12 & 1,07 & 1,21 & 0,97 & $1,22 \mathrm{a}$ \\
\hline BR700 & 1,41 & 1,49 & 1,26 & 1,54 & 1,19 & 1,28 & 1,10 & 1,07 & $1,29 a$ \\
\hline BR601 & 1,02 & 1,25 & 1,37 & 1,35 & 0,86 & 0,98 & 0,88 & 0,81 & $1,06 \mathrm{~b}$ \\
\hline Média & $1,25 \mathrm{AB}$ & $1,40 \mathrm{~A}$ & $1,34 \mathrm{~A}$ & $1,38 \mathrm{~A}$ & $1,06 \mathrm{BC}$ & $1,11 \mathrm{ABC}$ & $1,06 \mathrm{BC}$ & $0,95 \mathrm{C}$ & \\
\hline
\end{tabular}

${ }^{1}$ Médias seguidas pela mesma letra maiúscula na linha ou maiúscula na coluna não diferem significativamente entre si seguindo teste.

Teste SNK, $\mathrm{P}<0,05, \mathrm{CV}=18,48$

cursoras de outros compostos, como a lignina. Não foi encontrada correlação significativa entre a porcentagem de fenóis e a lignina, embora, em dois híbridos, tenha havido aumento no teor de lignina com o avanço do estádio de maturação.

Segundo Rodrigues (1996), com a utilização do método azul da Prússia, pode-se classificar os grãos que apresentarem níveis superiores a $0,70 \%$ como materiais com tanino e os grãos com níveis inferiores a $0,70 \%$ como materiais sem tanino. Admitindo-se que esse parâmetro seja válido para silagens, poderia se classificar as silagens dos três híbridos nos oito estádios como materiais com tanino. Apesar de os níveis de fenóis totais encontrados estarem acima do limite estabelecido por Rodrigues (1996), não foi encontrada correlação negativa com a DIVMS. Este achado pode ser um indicativo de que o padrão utilizado para grãos não é adequado para silagens, indicando a necessidade de se pesquisar esse parâmetro.

\section{Conclusões}

Houve alteração das frações fibrosas com o avanço da maturação, especialmente do terceiro para o quarto estádio. Com relação à lignina, houve diferença no comportamento dos híbridos, havendo aumento nos híbridos BR 601 e BR 700 com o avanço da maturidade; já para o híbrido AG 2006, não foi observada variação. A DIVMS também teve um comportamento diferente entre os híbridos, apresentando-se em níveis máximos da segunda à quinta semana para o híbrido AG 2006, da primeira à quinta semana, para o híbrido BR 700 e primeira a quarta semana, para o híbrido BR 601.

Mesmo nas silagens contendo tanino não foram observadas correlações entre o tanino e parâmetros de qualidade como a DIVMS.

\section{Literatura Citada}

ANDRADE, J. B.; CARVALHO, D. D. Estádio de maturação na produção e qualidade da silagem de sorgo. II - Digestibilidade e consumo da silagem. Boletim da Indústria Animal, Nova Odessa, v. 49, n. 2, p. 101-106, 1992.

BISHNOI, U. R.; OKA, G. M.; FEARON, A. L. Quantity and quality of forage and silage of pearl millet in comparison to sudax, grain, and forage sorghums harvested at different growth stages. Tropical Agriculture, London, v. 70, n. 2, p. 98102, 1993. 
BORGES, A .L. C. C . Qualidade de silagens de híbridos de sorgo de porte alto, com diferentes teores de tanino e de umidade no colmo, e seus padrões de fermentação. 1995. 104 f. Dissertação (Mestrado em Zootecnia) - Escola de Veterinária,Universidade Federal de Minas Gerais, Belo Horizonte.

BRUNO, O. A.; ROMERO, L. A.; GAGGIOTTI, M. C. et al. Cultivares de sorgos forrajeros para silaje. 1. Rendimiento de materia seca y valor nutritivo de la planta. Revista Argentina Producíon Animal, v. 12, n. 2, p. 157-162, 1992.

CARVALHO, D. D.; ANDRADE, J. B.; BIONDI, P. et al. Estádio de maturação na produção e qualidade da silagem de sorgo. 1. Produção de matéria seca e da proteína bruta. Boletim da Indústria Animal, nova Odessa, v. 49, n. 2, p. 91-99, 1992.

CUMMINS, D.G. Relationships between tannin content and forage digestibility in sorghum. Agronomy Journal, Madison, v. 63, n. 3, p. 500$502,1971$.

DANLEY, M. M.; VETTER, R. L. Changes in carbohydrate and nitrogen fractions and digestibility of forages: maturity and ensiling. Journal of Animal Science, Champaign, v. 37, n. 4, p. 994-99, 1973.

ESMAIL, S. H. M.; BOLSEN, K. K.; PFAFF, F. Maturity effects on chemical composition, silage fermentation and digestibility of whole plant grain sorghum and soya-bean silages fed to beef cattle. Animal Feed Science and Technology, Amsterdam, v. 33, n. 1/2, p. 79-85, 1991.

FAIRBAIRN, R.; ALLI, I.; PHILLIP, L. E. Proteolysis and aminoacid degradation during ensilage of untreated or formic acid treated luceme and maize. Grass and Forage Science Oxford, v. 47, n. 4,p. 382-390, 1992.
FERRARIS, R.; CHARLES-EDWARDS, D. A. A comparative analysis of the growth of sweet and forage sorghum crops. II. Accumulation of soluble carbchydrates and nitrogen. Australian Journal of Agricultural Research, Victoria, v. 37, n. 5, p. 513-522, 1986.

GAGGIOTTI, M. C.; ROMERO, L.A.; BRUNO, O. A. et al. Cultivares de sorgos forrajeros para silaje. II Características fermentativas y nutritivas de los silajes. Revista Argentina de Producion Animal, v. 12, n. 2, p. 163-167, 1992.

GOTO, M.; GORDON, A. H.; CHESSON, A. Changes in cell-wall composition and degradability of sorghum during growth and maturation. Journal of the Science of Food and Agriculture, London, v. 54, n. 1, p. 47-60, 1991.

HAHN, D. H.; ROONEY, L. W.; EARP, C. F. Tannins and phenols of sorghum. Cereal Foods World,St. Paul, v. 29, n. 12, p. 776-779, 1984.

HANNA, W. W.; MONSON, W. G.; GAINES, T. P. IVDMD, total sugars and lignin measurements on normal and brown mibrid (bmr) sorghums at various stages of development. Agronomy Journal, Madison, v. 73, n. 6, p. 10501052, 1981.

HART, S. P. Effects of altering the grain content of sorghum silage on its nutritive value. Journal Animal Science, Champaign, v. 68, n. 11, p. 3832-3842, 1990.

HORWITZ,W. (Ed.). Official methods of analysis of the Association of Official Analytical Chemists. 13.ed. Washington: Association of Official Analytical Chemists, 1980. 1080p.

HUNT, C. W.; KEZAR, W.; HINMAN, D. D.; COMES, J. J., LOESCHE, J. A., MOEN, T. Effects of hibrid and ensiling with and without a 
microbial inoculant on the nutricional characteristics of whole-plant corn. Journal of Animal Science, Champaign, v. 71, n. 1, p. 3843, 1993.

LEIBENSPERGER, R. Y. ; PITT, R. E. A model of clostridial dominancein ensilage. Grass and Forage Science, Oxford, v. 42, n. 23, p. 297-317, 1987.

LUSK, J. W.; KARAU, P. K.; BALOGU, D. O.; GOURLEY, L. M. Brown mibrid sorghum or corn silage for milk production. Journal of Dairy Science, Champaign, v. 67, n. 8, p. 1739-1744, 1984.

McBEE, G. G.; MILLER, F. R. Carohydrate and lignin partitioning in sorghum stems and blades. Agronomy Journal, Madison, v. 82, n. 7/8, p. 687-690, 1990.

McDONALD, P.; HENDERSON, A. R.; HERON, S. The Biochemistry of Silage. 2 ed. Marlow: Chalcombe, 1991. 340 p.

McDONALD, P.; HENDERSON, A. R. Buffering capacity of herbage samples as a factor in ensiling. Journal of the Science of Food and Agriculture, London, v.13, n. 7, p. 397-400, 1962.

MEESKE, R.; ASHBELL, G.; WEINBERG, Z. G. et al. Ensiling forage sorghum at two stages of maturity with the addition of lactic acid bacterial inoculants. Animal Feed Science and Technology, Amsterdam, v. 43, n. 3-4, p. 165175, 1993.

MINSON, D. J. Forage in ruminant nutrition. San Diego: Academic Press, 1990. 483 p.

MOISIO, T.; HEIKONEN, M. Lacticacid fermentation in silage preserved with formic acid. Animal Feed Science and Technology, Amsterdam, v. 47, n. 1, p.107-124, 1994.
MONTGOMERY, C. R., et al. Tannin concentration and quality changes in sorghum as affected by maturity and sorghum type. Crop Science, Madison, v. 16, p. 372-375, 1986.

MUCK, R.; O'KIELY, P. Aerobic deterioration of lucenie (Medicago satlva) and maize (Zea mays) silages. Effects of fennentation products. Journal of the Science of Food and Agriculture, London, v. 59, n. 2, p. 145-149, 1992.

NOGUEIRA, F. A. S. Qualidade das silagens de híbridos de sorgo de porte baixo com e sem teores de taninos e de colmo seco e suculento, e seus padrões de fermentação, em condições de laboratório. 1995. 78 f. Dissertação (Mestrado em Zootecnia) - Escola de Veterinária, Universidade Federal de Minas Gerais, Belo Horizonte.

OHSHIMA, V.; McDONALD, P. A review of the changes in nitrogenous compounds of herbage during ensilage. Journal of the Science of Food and Agriculture, London, v. 29, n. 6, p. $497-$ $505,1978$.

PAIVA, J. A. J. Qualidade da silagem da região metalúrgica de Minas Gerais. 1976. 85 f. Dissertação (Mestrado) - Escola de Veterinária, Universidade Federal de Minas Gerais, Belo Horizonte.

PEREIRA, O. G.; OBEID, J. A.; GOMIDE, J. A.; QUEIRÓZ, A. C. Produtividade de uma variedade de milho (Zea mays L.) e de três variedades de sorgo (Sorghum bicolor (L.) Moench) e o valor nutritivo de suas silagens. Revista da Sociedade Brasileira de Zootecnia, Viçosa, v. 22, n. 1, p. 31-38, 1993.

PETTERSON, K. L.; LINDGREN, S. The influence of the carbohydrate fraction and additives on silage quality. Grass Forage Sciencia, Oxford, v. 45, n. 2, p. 223-233, 1990. 
PRICE, M. L.; BUTLER, L. G. Rapid visual estimation and spectrophotometric determination of taimin content of sorghum grain. Journal Agricultural and Food Chemistry, Washington, v. 25, n. 6, p. 1268-1273, 1977.

ROGLER, J. C.; BUTLER, L. G. Enhancement of high tannin sorghum utilization: biological effects of dietary tannins. In: INTSORMIL Fighting Hunger with Research. Lincoln, [1993]. p. 145-149.

RODRIGUES, W. A. Variabilidade para teor de tanino em sorgo (Sorghum bicolor L.), seu controle genético e associação com a resistência à pássaros. 1991. 36 f. Dissertação (Mestrado em Zootecnia) - Escola Superior de Agricultura de Lavras, Lavras.

RODRIGUES, W.A. Tanino em sorgo: métodos de determinação e análise genética. 1996. $41 \mathrm{f}$. Tese (Doutorado) - Escola Superior de Agricultura “Luiz de Queiroz”, Universidade de São Paulo, Piracicaba.

SALAKO, S. A.; FELIX, A. In vitro dry matter and organic matter digestibilities of various cuitivars of grain sorghum and sweet sorghum silages. Journal Animal Science, Champagin, v. 63, p. 298, 1986. Suplemento.

SANDERSON, M. A. Aerobic stability and in vitro fiber digestibility of microbially inoculated corn and sorghum silages. Journal of Animal Science, Chamapaign, v. 71, n. 2, p. 505-514, 1993.

THORSTENSSON, E. M. G. Apparent inhibition to digestivo by lignin in normal and brown midrib stems. Journal of the Science of Food and Agriculture,London, v. 59, n. 2, p. 183-188, 1992.

TILLEY, J. M. A., TERRY, R. A. A two stage technique for the in vitro digestivo of forage crops. Journal of British Grassland Society, Oxford, v. 18, n.1,p.104-111, 1963.

TJANDRAATMADJA, M.; MacRAE, I. C.; NORTON, B. W. Intake and digestibility of sorghum silage by goats. Animal Feed of Science and Technology ,Amsterdam, v. 41, n. 3, p. 171179, 1993.

TONANI, F. L. Valor nutritivo das silagens de sorgo (Sorghum bicolor L.) em diferentes estádios de maturação dos grãos. 1995.56 f. Dissertação (Mestrado em Zootecnia) - Universidade Federal de Viçosa, Viçosa.

VAN SOEST, P. J. Nutritional ecology of the ruminant. 2 ed. Ithaca: Cornell University Press, 1994. $476 \mathrm{p}$.

VAN SOEST, P. J.; ROBERTSON, J. B.; LEWIS, B. A. Methods for dietary fiber, neutral detergent fiber, and nonstarch polysaccharides in relation to animal nutritivo. Journal of Dairy Science, Champaign, v. 74, p. 3583-3597, 1981.

ZAGO, C. P. Cultura de sorgo para produção de silagem de alto valor nutritivo. In: SIMPÓSIO SOBRE NUTRIÇÃO DE BOVINOS, 4., 1991, Piracicaba Anais... Piracicaba: FEALQ. 1991. p.169-217. 